\title{
Connectivism: Implications for Distance Education
}

\author{
Seyyed Kazem Banihashem,", and Khadijeh Aliabadi ${ }^{1}$ \\ ${ }^{1}$ Educational Technology, Department of Educational Technology, Faculty of Education and Psychology, Allameh Tabataba'i University, Tehran, Iran \\ "Corresponding author: Seyyed Kazem Banihashem, Educational Technology, Department of Educational Technology, Faculty of Education and Psychology, Allameh Tabataba'i \\ University, Tehran, Iran. Tel: +98-9147076354, E-mail: k.banihashem@atu.ac.ir
}

Received 2016 December 30; Revised 2017 July 01; Accepted 2017 September 06.

\begin{abstract}
Background: According to the connectivism learning theory, learning has a different form in the digital age compared to the industrial age, where traditional learning theories were applied. Thus, this study aimed at identifying and discovering implications of connectivism learning theory for distance education.

Methods: The present study was a qualitative research. Population of this study was all the documents that were published in Iran during 2007 and 2015. Based on this search, about 100 valid published academic materials including papers, books, websites, conferences, and other academic materials were recognized. Because of the large overlap of these materials, by using purposive sampling, 10 cases were selected as the research sample. In this study, Mayring's deductive qualitative content analysis method was used to extract implications of connectivism learning theory for distance education. According to the deductive model of qualitative content analysis, research question was identified in the first step. In the second step, valid and relevant publications and texts were determined. In the third step, aspects of theoretical analysis and categories were defined. In the fourth step, encoding of analysis units was done to infer the subcategories. In the fifth step, the main categories were extracted based on their most consistency with the subcategories; and in the final step, results were interpreted and quantitative assessment (e.g., frequencies) was done.

Results: The results of this study referred to 9 connectivism implications as follow: networked teacher, networked students, networked learning, ecosystem, information and knowledge stream, connection and interaction, pluralism, and value measuring.

Conclusion: Findings of this study may be useful and helpful for instructional and learning designers in e-learning environments.
\end{abstract}

Keywords: Learning Theory, Connectivism, Distance Education, Learning Implications, Learning

\section{Background}

The present era has opened new doors for researchers. Rapid and new advances in technology and science have made the globe to look like a village where advances do not stay away from the eyes of the world (1). Our community has witnessed a significant paradigm shift from industrial age to digital age. Our society has been rebuilt and transformed under the influence of science and technology (2). The society has witnessed a transition, a transition from the industrial age to the information age (3). Passing through the industrial age to the information age has obliged organizations to change step by step and in line with society (4); and educational organizations are not an exception. In this age, knowledge and learning is distributed and it can happen synchronously and asynchronously $(5,6)$. At this time, learners are parallel processors $(7,8)$. This age is called "digital age" by Siemens and in this stage, mankind can emancipate himself from the fence of time and location and can learn whenever and wherever he wants according to his needs and desires. This could have not been done before, but now thanks to using modern methods of teaching and learning which is called 'distance education', it can happen. Nowadays, the use of e-learning tools and information and communication technology (ICT) is growing strongly. According to Barbera (9), cited by Banihashem et al. (10), in many developed countries enrollment in distance learning courses compared to total enrollments in higher education in the United States during 2002 and 2007 were increased from $6.9 \%$ to $21.9 \%$. Hence, it can be stated that distance education introduces itself as the method that has been welcomed and succeeded in the 21st century. Distance education refers to the use of telecommunications technology to acquire knowledge and information aimed at teaching and learning (11). The major advantage of distance education is in interaction between learners and the educator and learner and learners through synchronous and asynchronous learning network models (12). Based on the theoretical principles, learning paradigms are in fact learning theories. Siemens indicated that comprehensive changes 
in the level and depth of the society have occurred and despite the uprising that education systems have shown, education domain has always acted weakly in recognition of the impact of new learning tools and identification of the environmental changes, which have a special meaning for the learners (13). One of the main reasons of this weak movement of education goes back to the current learning theories, behaviorism, and cognitive and constructivism (14). Siemens found that traditional learning theories are unable to explain learning that occurred through technologies in educational institutions. He indicated that traditional learning theories are not progressing as fast as technologies and they cannot explain the explosion of knowledge and how learning occurs in such an environment (15). Therefore, based on the constraints of traditional learning theories, Siemens in his famous article titled, "Connectivism: A new learning theory for the digital age" introduced a new learning theory (15). Connectivism learning theory claims that unlike traditional learning theories, it is able to simply answer questions that have been raised in the digital age that challenge learning theories (14).

The advent of connectivism learning theory in the 21st century has found its pros and cons. For example, Fenoglio (16) indicated that knowing and understanding connectivism as a learning theory indicates that it has a great potential to engage students in learning experiences. Massyn (17) believes that connectivism influences new learning environments. Verhagen, as one of the main critics of connectivism, indicated that connectivism is a pedagogical model at the curriculum level and it cannot be considered as a learning theory (18). In response to this criticism, Siemens refers to Mergel's emphasis on Ertmer's and Newby's five definitive questions to distinguish the theory. This attempt provides a framework to organize the learning theories (19):

1. How does learning occur?

2. What factors influence learning?

3. What is the role of memory?

4. How does transfer occur?

5. What types of learning are best explained by this theory?

Table 1 indicates how different theories relate based on Ermer's and Newby's questions.

Siemens also claims that a learning theory has an epistemological basis, which in this case "connective knowledge" is known as the epistemological basis of connectivism, which is presented by Downes (6). It is important to understand what connective knowledge is because it plays an important role in connectivism and e-learning design based on connectivism. Downes (6) pointed out that knowledge is created not only in quantitative (empiricism) and qualitative (rationalism) form, but also there is a third kind of knowledge that is formed by connections. Downes (6) further indicated that qualitative knowledge is a knowledge typically derived from the senses. The things we see, the things we feel, the things we hear: these are the qualities of an object. Quantitative knowledge is derived from the practices of counting and measuring. Nonetheless, connective knowledge as the third type of knowledge is described by connectivism. Connectivism is a theory that tells us what this third type of knowledge is, where it is, what produces it, how we learn it, and how it can be used.

Therefore, because of the importance of this theory in the digital age and because of the widespread use of distance learning, especially online learning in the digital age, it seems significantly important to identify implications and components of connectivism learning theory for distance education.

Connectivism believes that learning environments are complex and chaotic and they cannot be divided into simplified parts or into a mechanical level, but they should be viewed as a whole and alive organism (20). According to the connectivism learning theory, learning in the digital age occurs as a process of forming networks. Learning is a process of making nodes, linking the nodes together, and forming a network. In other words, knowledge and cognition are distributed among a network of people and technology, and learning is the process of connecting, developing, and performing these networks (21). Network learning is the term usually used to describe this concept (14). In network learning, the 3 concepts of nodes, networks, and ecosystems play an essential role. Node as the smallest unit of information can include information in the brain, a concept, a human, or a computer (22). Because there are different nodes, different networks are formed and connected networks interact in a bigger environment as a living organism called "ecosystems" (20).

To fully understand connectivism learning theory and extract the essential components of this theory that imply to e-learning and distance education, it is necessary to take the principles of this theory into consideration. Siemens (23) presented principles for connectivism learning theory, and understanding these principles will lead us to a profound perception of connectivism learning theory, they are as follow:

- First principle: Learning and knowledge rests in diversity of opinions.

- Second principle: Learning is a process of connecting specialized nodes or information sources.

- Third principle: Learning may reside in non-human appliances.

- Fourth principle: Capacity to know more is more critical than what is currently known. 
Table 1. Learning Theories (19)

\begin{tabular}{|c|c|c|c|c|}
\hline Property & Behaviorism & Cognitivism & Constructivism & Connectivism \\
\hline How learning occurs & $\begin{array}{l}\text { Black box, observable } \\
\text { behavior main focus }\end{array}$ & Structured, computational & $\begin{array}{l}\text { Social, meaning created by } \\
\text { each learner (personal) }\end{array}$ & $\begin{array}{l}\text { Distributed within a network, } \\
\text { social, technologically } \\
\text { enhanced, recognizing, and } \\
\text { interpreting patterns }\end{array}$ \\
\hline Influencing factors & $\begin{array}{l}\text { Nature of reward, } \\
\text { punishment, stimuli }\end{array}$ & $\begin{array}{l}\text { Existing schema, previous } \\
\text { experiences }\end{array}$ & $\begin{array}{l}\text { Engagement participation, } \\
\text { social, cultural }\end{array}$ & $\begin{array}{l}\text { Diversity of network, strength } \\
\text { of ties }\end{array}$ \\
\hline Role of memory & $\begin{array}{l}\text { Memory is the hardwiring of } \\
\text { repeated experiences, where } \\
\text { reward and punishment are } \\
\text { most influential. }\end{array}$ & Encoding, storage, retrieval & $\begin{array}{l}\text { Prior knowledge remixed to } \\
\text { current context }\end{array}$ & $\begin{array}{l}\text { Adaptive patterns, } \\
\text { representative of current } \\
\text { state, existing in networks }\end{array}$ \\
\hline How transfer occurs & Stimulus, response & $\begin{array}{l}\text { Duplicating knowledge } \\
\text { constructs of "knower" }\end{array}$ & Socialization & Connecting to (adding) nodes \\
\hline $\begin{array}{c}\text { Types of learning best } \\
\text { explained }\end{array}$ & Task-based learning & $\begin{array}{l}\text { Reasoning clear objectives, } \\
\text { problem solving }\end{array}$ & Social, vague (ill defined) & $\begin{array}{l}\text { Complex learning, rapid } \\
\text { changing core, diverse } \\
\text { knowledge sources }\end{array}$ \\
\hline
\end{tabular}

- Fifth principle: Nurturing and maintaining connections is needed to facilitate continual learning.

- Sixth principle: Ability to see connections between fields, ideas, and concepts is a core skill.

- Seventh principle: Currency (accurate, up-to-date knowledge) is the intent of all connectivist theories.

- Eighth principle: Decision-making is itself a learning process. Choosing what to learn and the meaning of incoming information is seen through the lens of a shifting reality. While an answer may be right today, it may be wrong tomorrow due to alterations in the information climate affecting the decision.

Studies have been done on the role of connectivism learning theory in education in different sectors. For example, see researches of Margaryan, Bianco and Littlejohn (24), Clara and Barbera (25), Duke, Harper and Johnston (22), Anderson and Dron (26), Kop and Hill (27), Milligan, Littlejohn and Margaryan (28), Rezaei, Nili, Fardanesh and Shahalizadeh (29), Farajolahi, Esmaeili, Sarmadi and Ganbari (30), Kalantari and Saeedipoor (31), Aliabadi and Khazayi (32), Hagshenas (33), Zarei (34), Rezayi, Nasri and Armand (35), Eskandari, Fardanesh and Sajjadi (13). Nevertheless, no qualitative research directly addressed connectivism learning theory implications for distance education according to the existing literature. Therefore, considering the importance of this theory in the digital age as well as the prevalence of distance learning, especially MOOCs in the digital age, and also given the gap in identifying the implications of this theory for distance education, the present study was conducted to extract implications of connectivism learning theory for distance education.

\section{Methods}

This study was a qualitative research. In a qualitative research, the researcher infers his/her propositions form the literature (36). In the present study, Mayring's (37) deductive model of qualitative content analysis was used as the research method. Deductive model was used because in this model, the researcher uses the existing theories to identify and encode them to extract intended categories (38). Based on this model, in the first step, we identified the research question. In the second step, all valid contents and publications related to the subject were determined; and for this research, population of this study was all the documents published in Iran during 2007 and 2015. Based on the search, about 100 valid published academic materials including papers, books, websites, conferences, and other academic materials were recognized. Because of the large overlap of these materials, using purposive sampling, 10 cases were selected as the research sample. Purposive sampling was used because in a qualitative study, the researcher is looking for the samples, which are perfectly aligned with the purpose of the study and the researcher does not seek to generalize the results. In the third step, we defined aspects of theoretical analysis. In the fourth step, coding of the analysis units was done to extract the subcategories. In the fifth step, according to the subcategories, the categories were extracted and we extracted the category based on the relevancy of subcategories. In the final step, the results were interpreted and the frequencies of the categories determined. The 3 main criteria for entering this research were being relevant, valid, and published in the country. Exclusion criteria were shortage of clear results and having overlap with other samples. 


\section{Results}

The results of this qualitative content analysis study are as follow. Table 2 shows categories and subcategories extracted by deductive model of qualitative content analysis along with coding units and sample of analysis.

As demonstrated in Table 2, nine main categories were extracted from the deductive model of qualitative content analysis. These main categories are as follow: networked teacher, networked student, knowledge flow, selforganization, interaction and connection, pluralism, networked learning, ecosystem, and value measuring. Table 3 displays the frequency of categories extracted from qualitative content analysis.

As illustrated in Table 3, interaction and connection was the most frequent category in qualitative content analysis, with a frequency of 26 . On the other hand, selforganization was the least frequent in the lowest rate among categories, with a frequency of 9 .

\section{Discussion and Conclusion}

Explosion growth of information and reduced half-life of knowledge require the students to be involved in a dynamic process of lifelong learning and constantly develop their knowledge throughout their lives (30). Such fulfillment would not be expected from conventional linear patterns. Network and distributed knowledge require special models of instructional design, which are not linear but are in a networked form. As Siemens (23) claimed, connectivism learning theory belongs to the digital age. The world's knowledge doubled every 10 years before, but now it doubles every 18 months (15). Kop and Hill (27) believe that connectivism learning theory is not limited to online environment; however, online environment is one of the most important fields in which connectivism learning theory can be applied and prospered. Online learning and distance education are considered as one of the important educational models that are expanding day by day and have become widespread. On the other hand, connectivism learning theory is in line with distance learning environments' features. This composition has already led to formulation of a new format of distance education called "MOOC" (Massive Online Open Course) (39). Therefore, the present study aimed at focusing on extracting implications of connectivism learning theory for distance education. The results of deductive model of qualitative content analysis are presented in 9 main categories, which are as follow: networked teacher, networked student, knowledge flow, self-organization, interaction and connection, pluralism, networked learning, ecosystem, and value measuring.
With a historical look at education, we found that teachers have played an important role in the educational process in all ages. According to connectivism, in the digital age and in distance learning environments, the role of the teacher is defined in a network format (40). In the networked teacher model, the teacher creates nodes with colleagues for professional development, public media, printed and digital resources, local community, blogs, wikis, video conferencing, chat rooms, social networks, social bookmarking, content, and more (29). The formation of this network provides a personalized professional learning environment for teachers (20).

Drexler (41) introduced student network model inspired by a teacher network model to support constructive learning environments. Although this model is based on the support of constructivist theory, it has the closest relationship to the connectivism instructional design models (29). In connectivist online learning environments, student focuses on creating academic social relations through synchronous and asynchronous tools. Information management helps the networked student to value resources, search resources, access to free resources, and use RSS tools for social bookmarking, tagging, readership sharing, and social networking.

Siemens stated that developing a network and its nodes depends on the flow of knowledge and information within the network (14). When a student deals with other nodes on an issue, the flow of knowledge occurs. In other words, exchange of information between the nodes of a network represents the flow of knowledge. Therefore, in connectivism- based learning environments, flow of knowledge and information across networks leads to the dynamism, prosperity, growth, development, and network capability.

According to the theory of chaos and complexity, all complicated adaptive systems can operate in one of the following 3 areas: the stable region, the unstable region, and the edge of the chaos, which is a narrow transition region between the first 2 cases. In the stable region, stiffness and numbness, and in the unstable region, collapsing is expected. In the edge of chaos, spontaneous self-organizing processes occur and innovative behavior patterns emerge (30).

One of the most prominent features of connectivism is interaction and connection. As we come close to connectivism learning theory and walk away from traditional learning theories, the role of interaction and communication become more intense (41). Connection and interaction refers to links of nodes in a network that provides the flow of information and knowledge. The robustness of the connection and interaction between nodes makes the information and knowledge flow more rapid. In fact, the con- 
Table 2. The Results of Qualitative Content Analysis

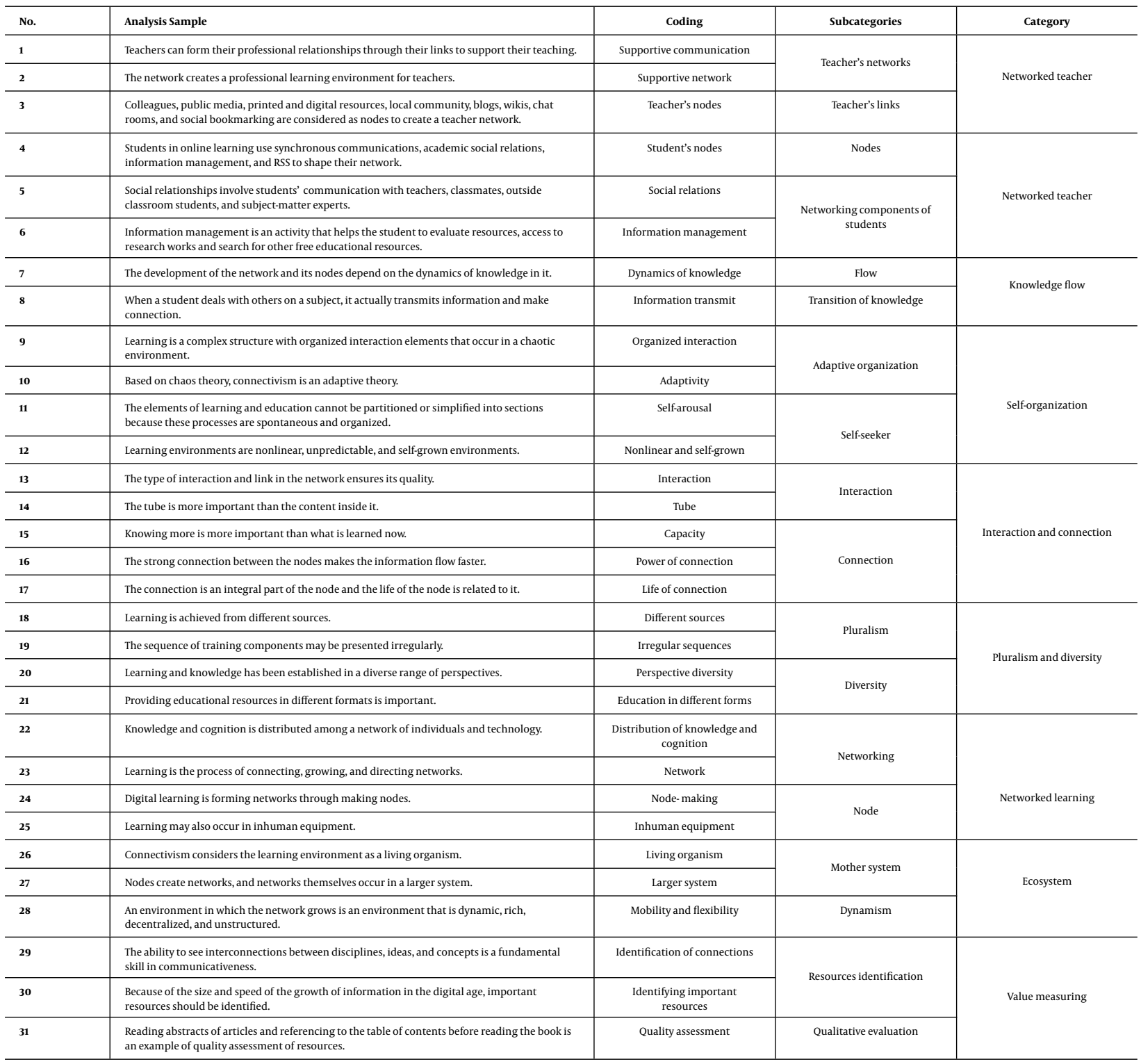

nection and interaction is an integral part of a node. Based on the theory of connectivism and considering the importance of connection and interaction in connectivism, distance education should consider the highest value for connection and interaction.

The theory of connectivism criticizes traditional learning theories for simplifying learning and replacing the notion of pluralism (20). According to connectivism, learning cannot be simplified and divided because learning resides in a chaotic environment with complex elements (20). Connectivism- based online learning emphasizes teaching and learning in diverse forms to make more rich networks. The presentation and introduction of various educational resources provide many opportunities for students of a class. Various nodes cause the formation of diverse networks. Pluralism and diversity refers to the first principle of connectivism: "Learning and knowledge rests in diversity of opinions."

Connectivism believes that learning in the digital age is the process of formation of networks (14). Knowledge and cognition is distributed among a network of individuals and technology, and learning is the process of linking, 
Table 3. The Frequency of Categories

\begin{tabular}{|c|c|c|c|}
\hline No. & Subcategories & Category & Frequency \\
\hline $\mathbf{1}$ & Teacher's networks-Teacher's links & Networked teacher & 16 \\
\hline 2 & Nodes-networking components of students & Networked student & 18 \\
\hline 3 & Flow- transition of knowledge & Knowledge flow & 12 \\
\hline 4 & Adaptive organization-self-seeker & Self-organization & 9 \\
\hline 5 & Interaction- connection & Interaction and connection & 26 \\
\hline 6 & Pluralism- diversity & Pluralism & 13 \\
\hline 7 & Networking- node & Networked learning & 24 \\
\hline 8 & Mother system- dynamism & Ecosystem & 17 \\
\hline 9 & Resources identification- Qualitative evaluation & Value measuring & 15 \\
\hline
\end{tabular}

developing, and directing these networks (15). This definition refers to the various principles of connectivism (Principles 1, 2, and 3). Online learning based on connectivism does not deal with the transfer of information; instead, it provides an environment, where learners can access network nodes and gain access to learning through the interaction, communication, and flow of knowledge.

Ecosystem refers to a larger system in which the related networks interact with one another. Ecosystem is a mother system that acts as a living organism in the dynamics, enrichment, mobility, and growth of its subset networks. Siemens believes that ecosystems and networks can be good alternatives to the current hierarchical and classical models of education (23). The duty of the educators is to create and strengthen the ecosystem so that the learners in this ecosystem can network with different nodes and show better performance. Therefore, distance education should create an ecosystem that allows the emergence of innovation and leads to the creation of the most diverse mixes and networks. Siemens used concept of "learning ecosystem design" to explain his process of designing for learning (15). Connectivism uses 'learning ecosystem design' concept instead of 'instructional systematic design' (which are emphasized by cognitive theories) and 'design of learning environments (which is emphasized by constructivism) to explain how to design education.

Another most important feature of connectivism is value measuring. Value measuring refers to assessing and checking the quality of one or more nodes inside the network before making a node (29). Due to the volume and speed of the growth of information in the digital age, the learner is expected to assess the quality of the nodes that they intend to connect with before they begin the learning process. Therefore, in connectivism theory, none of the nodes in a network has the value of spending time and energy and only valuable nodes should be selected for con- nection (15). Reading an abstract of a paper before reading the whole paper to check and evaluate whether it is worth to be read or not, is an example of values measuring.

In conclusion, connectivism learning theory is a young and new theory with new features that opens a new door for educational researches, specifically in distance education. The result of this study may help educational researches in distance education and online learning to have a better perspective when they look at this area of education with a connectivist glass.

\section{Footnote}

Conflict of Interest: None declared.

\section{References}

1. Baniashem K, Badali. M. , Ajami M, editors. The effectiveness of using e-portfolio on academic self-concept of students [in Persian]. 8th International Conference of E-learning. 2014; Iran, Tehran. .

2. Castells M, Cardoso G. The network society: From knowledge to policy. Washington, DC: Johns Hopkins Center for Transatlantic Relations; 2006.

3. Bell F. Connectivism: Its place in theory-informed research and innovation in technology-enabled learning. Int Rev Res Open Dist Learn. 2011;12(3):98-118. doi: 10.19173/irrodl.v12i3.902.

4. Aslan S, Reigeluth CM. Educational technologists: Leading change for a new paradigm of education. Tech Trends. 2013;57(5):18-24. doi: 10.1007/s11528-013-0687-4.

5. Ahern T, Leavy B, Byrne PJ. Complex project management as complex problem solving: A distributed knowledge management perspective. Int $J$ Proj Manage. 2014;32(8):1371-81. doi: 10.1016/j.ijproman.2013.06.007.

6. Downes S. Types of knowledge and connective knowledge. Half and Hour. [en línea] 2008. Available from: http://halfanhour.blogspot. com.

7. Jones $\mathrm{C}$, Shao $\mathrm{B}$. The net generation and digital natives: implications for higher education. 2011

8. Prensky M. Digital Natives, Digital Immigrants Part 1. On the Horizon. 2001;9(5):1-6. doi: 10.1108/10748120110424816. 
9. Barbera E. Mutual feedback in e-portfolio assessment: an approach to the netfolio system. Br J Educ Technol. 2009;40(2):342-57. doi 10.1111/j.1467-8535.2007.00803.x.

10. Banihashem K, Farokhi Tirandaz S, Shahalizadeh M, Mashhadi M. The Effect of E-learning on Students' Creativity [In Persian]. Mag E-learn Dist acad. 2014;5(4):53-61.

11. Anderson T. The theory and practice of online learning. Athabasca University Press; 2008.

12. Yazdi SM, Zandkarimi G. The Impact of E-Learning on some Psychological Dimensions and Academic Achievement. Int J Educ Learn. 2013;2(2):49-56. doi: 10.14257/ijel.2013.2.2.05.

13. Eskandari H, Fardanesh H, Sajjadi SM. Connectivism: in competition or alignment with other learning theories [in Persian]. Educ Psychol J. 2011;5(15):120-35

14. Siemens G. Complexity, Chaos and Emergence 2009. [updated 19 Oct 2009]. Available from: https://docs.google.com/document/d/ 1SbKRX97g1tVgxE3gVWIvA8injDYe_9JVwGjYCLzXe3k/edit.

15. Siemens G. Connectivism: A learning theory for a digital age. Intl J Instruct Technol Dist Learn. 2005;2(1):1-13.

16. Fenoglio P. Pinball' engagement and Connectivism: New understandings of learning in the 21st Century. 2006

17. Massyn L. A framework for learning design in different modes of delivery in an adult learning programme. University of the Free State; 2009.

18. Verhagan B. Connectivism: a new learning theory? 2006. Available from: http://elearning.surf.nl/e-learning/english/3793.

19. Siemens G. Learning and knowing in networks: Changing roles for educators and designers. ITFORUM for Discussion. 2008;27:1-26.

20. Eskandari $\mathrm{H}$. Theory and practice of educational media in digital age [in Persian]. Tehran: SAMT publication; 2011.

21. Siemens G, Tittenberger P. Handbook of emerging technologies for learning. Manitoba, Canada: University of Manitoba; 2009.

22. Duke B, Harper G, Johnston M. Connectivism as a digital age learning theory. The International HETL Review. 2013:4-13.

23. Siemens G. Connectivism: Learning theory or pastime of the selfamused. Manitoba, Canada: Learning Technologies Centre; 2006.

24. Margaryan A, Bianco M, Littlejohn A. Instructional quality of massive open online courses (MOOCs). Comput Educ. 2015;80:77-83. doi 10.1016/j.compedu.2014.08.005.

25. Clarà M, Barberà E. Learning online: massive open online courses (MOOCs), connectivism, and cultural psychology. Dist Educ. 2013;34(1):129-36. doi: 10.1080/01587919.2013.770428.

26. Anderson T, Dron J. Three generations of distance education pedagogy. Int Rev Res Open Dist Learn. 2011;12(3):80-97. doi: 10.19173/ir- rodl.v12i3.890.

27. Kop R, Hill A. Connectivism: Learning theory of the future or vestige of the past? Int Rev Res Open Dist Learn. 2008;9(3) doi: 10.19173/irrodl.v9i3.523.

28. Milligan C, Littlejohn A, Margaryan A. Patterns of engagement in connectivist MOOCs. J Online Learn Teach. 2013;9(2):149.

29. Rezaei E, Nili M, Fardanesh H, Shahalizadeh M. Qualitative Content Analysis of Connectivism Theory and Introducing a Conceptual Model of Learning Ecology Design [In Persian]. Mag E-learn Dist acad. 2014;5(1):33-45.

30. Farajolahi M, Esmaeili Z, Sarmadi MR, Ganbari A. Designing of learning quality model based on connectivism learning theory in Iran's Universities that are in charge of distance education [In Persian].J Learn Strat Med Sci. 2017;10(1):81-94.

31. Kalantari A, Saadipoor B. Study the effect of education based on connectivism on environment on learning and communication of students with nature in sixth grade [In Persian].JEnviron Educ Stable Deve. 2016;5(1):1-7.

32. Aliabadi $K$, Khazayi A. Distance education in digital age given to connectivism [In Persian]. J Educ Stud. 2015;4(2):43-54.

33. Hagshenas M. Application of media technologies in education: new paradaygm of learning in digital age [In Persian]. J Media Manag. 2015;16(5):36-43.

34. Zarei E. Knowledge and learning: connectivism theory [In Persian].J Inform Commun. 2011;3(4):141-53.

35. Rezayi E, Nasri S, Zrmand M. connectivism learning theory and it application in designing college textbook [In Persian]. J. Ayar. 2011;10(24):81-94

36. Flick U. Introducing research methodology: A beginner's guide to doing a research project. Sage; 2015.

37. Mayring P, Iman MT, Noshadi MR. Qualitative Content Analysis [28 paragraphs]. W. InForum Qualitative Sozialforschung/Forum: Qualitative Social Research 2000 [In Persian].J Res. 2011;3(2):15-45.

38. Wulf J, Blohm I, Leimeister JM, Brenner W. Massive Open Online Courses. Bus InfSystEng. 2014;6(2):111-4. doi: 10.1007/s12599-014-0313-9.

39. Baker-Doyle KJ. The networked teacher: How new teachers build social networks for professional support. Teachers College Press; 2011.

40. Drexler W. The networked student model for construction of personal learning environments: Balancing teacher control and student autonomy. Australasian J Educ Technol. 2010;26(3) doi: 10.14742/ajet.1081.

41. Wang Z, Chen L, Anderson T. A framework for interaction and cognitive engagement in connectivist learning contexts. Int Rev Res Open Dist Learn. 2014;15(2) doi: 10.19173/irrodl.v15i2.1709. 